\title{
FIVE WRITING DEVELOPMENT STRATEGIES TO HELP ACADEMICS FLOURISH AS WRITERS
}

\author{
J. Castle* \\ School of Education \\ e-mail: jane.castle@wits.ac.za
}

\section{Keane*}

Centre for Learning, Teaching and Development

e-mail: moyra.keane@wits.ac.za

*University of the Witwatersrand

Johannesburg, South Africa

\section{ABSTRACT}

Increasing the quality and quantity of published research has become an imperative for many universities in South Africa, but academic staff need more than policy mandates to flourish as writers. In this article the authors aim to inspire academic staff developers and research managers to initiate and support strategies to help academics write more and better, and to take pleasure in writing. Drawing on published literature and our own experiences, we turn a critical eye on writing development strategies used in our own research-intensive institution in Johannesburg, and strategies used in other institutions, mainly, but not only, in South Africa. We weigh up the benefits and drawbacks of five writing strategies: writing courses and workshops; writing groups; writing mentoring and coaching; PhD bootcamps; and writing retreats. We also provide a summary table of the claims made for particular strategies to promote capacity building and productivity, on the one hand, and emotional and social aspects of writing on the other hand. We conclude that by thinking critically and creatively, research managers and academic staff developers can indeed help academics to flourish as writers.

Keywords: writing development, writing strategies, writing courses and workshops, writing groups, writing mentoring and coaching, writing retreats.

\section{INTRODUCTION}

A host of books on research and academic writing, aimed at students and academic staff, testifies that writing is not easy. Even seasoned academics may struggle to write with ease and confidence (Boice and Jones 1984). Kapp, Albertyn and Frick (2011) observe that graduate students are often expected to write manuscripts worthy of publication without being taught how to achieve this goal. Many academics experience the process of writing as mysterious, daunting and unsupported (Moore, Murphy and Murray 2010). Some speak of feelings of 
loneliness and isolation when writing (Grant and Knowles 2000). Others have difficulty in prioritizing and legitimizing writing time in working hours (Badenhorst, Penny, Peckett, Joy, Hesson, Young, McLeod, Vaandering and Li 2013).

The aim of this article is to encourage research managers and those involved in the professional development of academic staff to think creatively and critically about writing development strategies and the possibilities they offer for the personal and professional growth of academics. The research question we address is 'How may those entrusted to provide professional writing support for academics help them flourish as writers? Our aim is not simply to persuade research managers and academic staff developers to make pragmatic decisions about which writing development strategies to promote in their institutions so as to meet the university's target for research publications. Instead we offer a space for active and critical engagement around strategies that shape the work of writing development in academics, particularly those who are completing higher degrees and beginning to write for publication.

We choose to illustrate writing development strategies with examples drawn mainly, though not exclusively, from our own institution and the South African published literature. Thus our aim is to stimulate dialogue and reflection about appropriate and effective writing development strategies for academics by presenting examples developed and applied in South African contexts.

The five strategies we review in this article include: writing courses and workshops; writing groups; writing mentoring and coaching; $\mathrm{PhD}$ bootcamps; and writing retreats. Writing is central to the research process in all five strategies. We begin by framing writing development strategies in the high pressure context of our university, then draw on international literature on the difficulties associated with writing, and the aspects of writing which academics like and dislike. We introduce our research design and process, then move on to a discussion of five writing strategies. We conclude the article with a table which summarises the claims that can be made for the main benefits and drawbacks for the five strategies.

\section{THE CONTEXT}

Over the past fifteen to twenty years, both nationally and internationally, declining government funding for public universities has led to ever-increasing workloads and declining resources for academics. In addition to their traditional duties of teaching and conducting research, academics are now involved in a wide range of professional and administrative activities, including representing their departments in university committees, providing professional expertise and policy advice to civic and community organisations, and engaging with the media. Academics 
are also under pressure to raise money for the university through publication and research grants (Dickson-Swift, James, Kippen, Talbot, Verrinder and Ward 2009, 229-230).

In our institution, which describes itself as a 'world class' 'research intensive' university, the number of students has more than doubled in the past decade, and stands at 36500 in 2016. The number of academic staff on permanent contracts remains below 1000 . In consequence, class sizes have grown larger, and lecturers' teaching and supervision workloads have increased exponentially. There are also urgent calls within the institution and beyond to address the changing demographics and preparation of both students and academic staff. The university needs to increase income from research and publication, and raise prestige (and income) by attracting, retaining and graduating more students and staff with higher degrees. Staff are, therefore, under ever-mounting pressure to deliver more (more research, more higher degree completions, more publications) with fewer resources (time, space, money). Thus the time is ripe to look at writing development strategies to help academics flourish as research writers.

It is sometimes assumed, for example by Singh (2012), that in established, 'researchintensive' universities in South Africa there is a vigorous culture of research across disciplines and departments, and that support for research writing is readily available to academics and postgraduate students in the form of research methodology courses, writing centres, writing courses and retreats. However, this is not always the case, particularly in 'professional schools' (such as law, engineering, accountancy or management) where there may be little tradition of research and writing for publication. Until recently there was no expectation that accountants or managers or even teachers should engage in research and produce scholarly publications. Almost all academics in our institution are forced into writing for publication and completing higher degrees to generate subsidy for the institution and to increase its standing in league tables. Academic staff have to become researchers and writers while carrying heavy teaching and administrative loads. This puts them under enormous stress.

\section{CONCEPTUAL FRAMEWORK}

\section{Assumptions}

The authors proceed from a humanist assumption that people are creative, resourceful and whole. We believe that by inviting research managers and colleagues responsible for the professional development of academic staff to reflect critically and creatively on writing development strategies, they can be sensitized to alternative ways of fulfilling their roles, and encouraged to initiate additional or alternative strategies, for example writing strategies. This may lead to their enhancing the quality of support and development they offer to academic staff 
in the institutions in which they work.

An additional assumption underlying this research is that universities have focused too much on writing strategies to increase productivity, status and income, rather than nurturing the personal and social dimensions of writing which may lead to authentic professional development, as Dwyer, Lewis, McDonald and Burns observe (2012, 132).

\section{Research writing}

Research writing is central to academic life, and academics are under increasing pressure to write, as the saying 'publish or perish' vividly illustrates. Yet academics need more than policy mandates and institutional visions to be, and remain, productive research writers.

Reasons why academics (should) write are not made explicit in our institution beyond the injunction to bring in subsidies and contribute to higher rankings in national and international league tables. These two 'drivers' for increasing publication rates are grounded in the supposition that academics write to produce new knowledge, to stay current with research literature and critique it, to collaborate with researchers nationally and internationally in solving problems rooted in theoretical and practical issues, to contribute to the design and implementation of innovations, to advise policy makers, to document ideas and reflections which have been peer reviewed, to contribute to the renewal and preservation of culture, to advocate, agitate, educate and contribute to social, political and intellectual debates in society. On an individual level, academics write for their own intellectual and creative fulfilment, as an expression of their academic identity, for the satisfaction of collegial collaborations, as well as for career advancement.

\section{Institutional context and support for writing}

Working in a supportive organisational culture may be a pre-condition for writing (Thomson and Kamler 2013, 7-8). Yet Murray (2012), Dickson-Swift et al. (2009) and others observe that although research and writing are important for institutions, time and space for them is often absent from academic workloads and workplaces, almost as if research were a hobby or pastime. First there has to be time to do the research, then a supportive culture for research writing needs to be created. This requires initiative and active support from communities of scholars, as well as those entrusted with the professional development of academic staff.

In addition to the absence of time, space and opportunity to write, there is often lack of supervision, mentoring and support for research and writing, even in research intensive universities (McGrail, Rickart and Jones 2006). So there are many academics and postgraduate 
students today, even in research-intensive universities, who do not have access to the opportunities and experiences which could lead them to be productive and successful writers.

The literature reviewed above establishes two issues: first there is a need to affirm the place of research and writing in the work of academics by establishing it as 'business as usual', that is, making time and space for it in workload planning and policy documents, as Lee and Boud (2003) advocate. Second, new strategies have to be found to support writing and writers, and to make writing more enjoyable and rewarding. It is the second issue, the matter of developing supportive strategies for writing, such as providing conducive spaces, sanctioned time and encouraging networks of peers that we are concerned with in this article.

\section{'Problems' with research writing}

Traditionally, in Britain and its former colonies, including South Africa, academic writers were either self-taught (toiling in isolation, under occasional direction from a supervisor, to complete a thesis by trial and error or by mimicry) or they served a kind of apprenticeship to a more experienced researcher who had mastered the skills of writing for publication and was willing to pass them on (Thomson and Kamler 2013). These processes were arduous and not always effective or enjoyable (Boice and Jones 1984). New ways were sought to teach writing, combining problem-solving and experiential approaches to learning with insights from education and psychology to help writers master important aspects of writing, including the techniques of writing, and ways of making thoughts and ideas visible and meaningful to others (Thomson and Kamler 2013; Aitchison and Lee 2006; Elbow 1981).

Murray and Moore (2006, 28-29) put forward five reasons why academics often dislike writing, based on surveys of Scottish and Irish participants in writing events held in their institutions. The results of their study confirm pioneering work in this area by Boice (1990) and Elbow (1973) in the USA, and resonate with accounts from Badenhorst $(2007 ; 2008)$ in South Africa of the 'barriers' which need to be broken by academics and higher degree students. These are the reasons Murray and Moore give for academics not writing:

1. The feeling of being forced to write by the institution, and the sense of harsh critical scrutiny imposed on writers who submit their work for review in journals. The feeling of being pressured to write and the association with judgmental review creates a kind of paralysis, or reluctance to begin or carry on writing.

2. The feeling of inertia or difficulty with getting started. Writers experience difficulty 'getting down to it' perhaps because writing is not often a scheduled part of an academic's workload, like teaching or meetings.

3. A feeling of getting stuck or blocked, or difficulty moving from one phase or type of writing to another. There are obstacles, real or imagined, that prevent people from writing. The 
feeling of being blocked is unpleasant and difficult to shift.

4. Lack of confidence about writing skills, processes and outputs. Academics' self-esteem and self-belief may be vulnerable, especially in highly pressured and competitive environments. Many academics feel they lack the knowledge and skill to write with competence.

5. Difficulties associated with finding one's voice. This feeling arises when an academic believes she has nothing to say, or is not sufficiently articulate to express what she wants to say. Some writers feel that their voice is stifled by the conventions of writing in a particular disciplinary style.

To this list, we might add the difficulties expressed verbally and in writing by both early career and seasoned academics who take part in writing events offered by our academic staff development centre about expressing themselves clearly and grammatically in English, often their second or third additional language, and finding their distinctive voice when writing in an 'additional' language. The persistently poor quality of education for black and coloured South Africans in many township and rural schools may also contribute to perceptions that writing is a difficult and unrewarding activity.

Murray and Moore (2006) refer to the emotional dimensions of academics' 'dislikes' and indicate that overcoming them will not be achieved by ignoring them. They have to be recognised, addressed and tackled. Murray and Moore stress the importance of starting with the things people like about writing and building on them so that there are more positive than negative feelings about writing.

So, what do academics like about writing? Murray and Moore (2006, 24-27) and Murray (2013) drawing on international research and theory suggest the following:

- Interactivity and dialogue with others (that is, talking with others about research through personal or virtual interactions)

- Knowledge creation and extension

- $\quad$ Achievement, output and approval

- $\quad$ Engagement and getting into the 'flow' of writing.

Murray's observations resonate with our own insights into why many academics dislike or avoid writing, and are echoed by South African writers such as Badenhorst (2007; 2008; 2010) and Kapp et al. (2011). We turn now to the design of the research.

\section{RESEARCH DESIGN AND PROCESS}

Our interest in writing development strategies stems from our past experiences of participating in writing courses and writing retreats, as both facilitators and writers. In late 2012 we embarked 
on an enquiry into the published literature on writing development strategies with the aim of informing policy and practice in our centre and institution. We held a four-day writing retreat in a Johannesburg country house in which we sourced, read, analysed and discussed published literature, both local and international, on a variety of writing strategies. We analysed the literature by searching for statements or perceptions concerning:

- $\quad$ characteristics of the context and participants in the writing strategy;

- the pedagogy employed to develop writing;

- claims and evidence to support the efficacy of the strategy.

As educators with a strong professional interest in writing pedagogy we were also alert to instances where Murray’s 'likes’ and dislikes’ were reported in the literature.

Our initial purpose was to deepen our own understanding of the writing development strategies in which we were engaged as planners and facilitators, using the methods of document analysis and participant observation. We wanted to know why a particular writing strategy might be adopted by an academic department, or by an institution, to address a particular problem or purpose, in a particular context, at a particular time (Merriam 2009). We reflected critically on how our reading and understanding of writing strategies differed from, or were similar to, those of other writers. We examined our own willingness to question our assumptions and consider alternatives. We then engaged in dialogues with colleagues in our institution's School of Education and in our academic staff development centre in order to solicit alternative views to our own. We also reviewed data we had collected in formative and summative evaluations of writing events held in our staff development centre between 2011 and 2015

We turn now to our analysis of the different strategies for supporting writing that we had identified in the literature. We describe the strategies in terms of their characteristics and the pedagogy employed. Later in the article we offer a table summarising issues around the efficacy of the strategies.

\section{WRITING STRATEGIES}

\section{Writing courses and workshops}

There are wide variations in the way that writing courses and workshops for academic staff are conceptualised and designed. They often provide technical advice and support for research and writing, especially writing for publication. Many courses include practical exercises to establish 
productive writing habits and patterns to be carried over into everyday practice once the course is finished. In addition to improving writing, courses which take place over a number of days may also address participants' lack of confidence in their ability to write, as well as feelings of isolation, by promoting learning from and with others in small groups (MacLeod, Steckley and Murray 2012; Devlin and Radloff 2014). Weaver, Robbi and Radloff (2013) believe that a 'structured writing programme' can demystify the publication process and provide support for writing by combining regular meetings, pre-set writing tasks and peer feedback on draft work. They concede that the multiple pressures on academics mean that the original goals they articulate in courses may not be sustained over a longer period of time.

Stellenbosch University’s five-day Writing for Publication 'retreat workshop' is highly structured. It provides dedicated, indeed sanctioned, time and space in a comfortable hotel off campus so that writers may escape the distractions of work and family life. The workshop offers 'hands-on coaching', or instruction, to help aspirant writers to overcome their fear of rejection and lack of knowledge and skill in scholarly writing (Kapp et al. 2011, 741). The majority of participants are from the host institution, but writers may come from other universities, and from varied disciplines. Participants are required to bring with them to the workshop a 'seventy percent complete' journal article. Academics are introduced to the purpose of academic journals, analysis of journal submission guidelines, common errors, characteristics of good writing, barriers to writing, and guidelines for writing the various components of a journal article.

Participants are grouped in discipline-oriented review and feedback groups which consist of three participants led by a critical reader and a language editor. There are practical writing exercises and dedicated time for writing, with support provided by language and disciplinary experts. The workshop also provides 'aftercare', in which participants continue working on articles they have not managed to complete during the workshop. Aftercare is available by appointment or email from the critical reader or language editor of the discipline-oriented group to which the writer was assigned. Written course evaluations completed at the end of the workshop, and later, indicate that participants gained skills and confidence in writing from the workshop, as well as a sense of self-efficacy. Participants also attested to the benefits of interaction with and feedback given by expert readers and editors.

Badenhorst's research and dissertation writing courses (2007; 2008) were developed initially as self-help guides for academic writers at the University of the Witwatersrand, and later adapted as flexible workshops and retreats for small groups of academic staff of Wits. These courses have a different orientation from Kapp et al.'s (2011) structured retreat 
workshops, as they combine both traditional and creative approaches to writing (Janks 2012) and conceptualise writing as knowledge-generating ('writing begets writing') rather than knowledge-recording (Aitchison and Lee 2006). Badenhorst's approach is loosely structured around three principles: conceptualising research; thinking creatively; and writing. Her course aims to help writers develop insights and skills in writing, reflect on their own and others' writing and develop an internal locus of control.

Badenhorst's Research Writing course offers writers techniques to deal with procrastination; the nature and structure of different types of academic text (journal articles, dissertation, thesis); productive writing habits; aspects of publishing acumen (understanding genre and discourse, choosing journals); argument; developing a distinctive voice; dealing with rejection and criticism; the writer's identity; and writing in groups. The pace and structure of Badenhorst's course can be adapted to suit the needs of different groups (see also Castle and Keane 2012; Janks 2012).

While the Writing for Publication retreat workshop described by Kapp et al. (2011) is structured, fast-paced and didactic, Badenhorst's course is more process-oriented, self-directed and exploratory in nature. Both types of workshop offer a visible (to research and finance managers) constructive, often enjoyable, and sometimes measurable way to increase writing activity and develop knowledge and skills in individuals and groups which may be practised during the course, and developed further afterwards. They are a legitimate way for writers to claim time and space for writing and writing development in the course of the normal academic workload. By providing opportunities for talking about writing and for giving and receiving feedback, such courses and workshops may also increase academics' self-confidence and motivation to write, and prepare them to meet challenges, rather than resist them (Moore 2003; Aitchison and Lee 2006).

A criticism of writing courses and workshops that we have heard voiced by conservative academics in our institution who reject learning support and writing development events provided by non-disciplinary specialists, is that they pamper or 'spoonfeed' participants, increasing dependency on supervisors, while undermining the ideal of the autonomous researcher. There is also a difficulty with sustaining the momentum and fluency gained in a workshop or course when academics return to 'normal duty'. Writing workshops and courses may inadvertently reinforce the view that certain groups of academics, such as women, emerging researchers, second language speakers of English, or academics in certain disciplines, are deficient or problematic, and therefore in need of remediation (Grant 2006; Grant and Knowles 2000; Moore 2003), a sensitive issue in South Africa with its enduring history of racial 
and gender oppression. In addition, some may argue that courses and workshops sustain the notion that there is one correct 'academic' way to write, and that writers need to be inducted into it.

An alternative point of view is that younger researchers, postgraduate students and women may be more open to innovative ways of being and writing which can be advanced in the give and take of courses and workshops. They may be the vanguard of new developments and pedagogies in universities, and new practices in writing for publication.

We turn now to writing groups.

\section{Writing groups}

Writing groups are a way of supporting individuals' motivation to write, to continue writing, and to finish a piece of writing, particularly after an intervention such as a writing course or workshop. Writing groups also disrupt the notion that academic writing takes place, or should take place, in isolation, in a dark garret, by a penniless author (Grant and Knowles 2000). Moore (2003) suggests that 'positive interdependence' of writers can be developed in groups when participants provide practical help and psychological support to one another. This is particularly important in a context where new cohorts of students and academics, new disciplines, new professional fields and new scholarly practices are developing to challenge the status quo (McGrail et al. 2006).

Advocates of writing groups argue that groups are a way of establishing, or maintaining, a collaborative community of writers, and also of developing new academic identities and new research cultures in universities (Lee and Boud 2003). Writing is a social act that benefits from discussion with others (Murray and Moore 2006). Members of cross-disciplinary writing groups can profit from the broad range of knowledge, experience and skills represented in the group.

In PaperHeaDs, Harrison (2011) tells the story of a group of ten women academics, both lecturers and researchers, based in Durban, who formed a peer learning and support group to sustain one another as they undertook doctoral study in education. In the context of infrequent research methods classes and pressure from supervisors to 'produce, produce, produce' for PhD forums, founding members initially came together to discuss pre-selected academic readings. Over time, the PaperHeaDs group focused less on formal discussion of reading and became an academic and emotional support group as well as a vehicle for the development of doctoral identity. Harrison explains that members shifted gradually, and organically, from being a community of practice (Lave and Wenger 1991; Wenger 1998) to something more like an 
'affinity group’ (Gee 2000) in which horizontal, democratic and networked relationships were developed through a combination of monthly meetings, a Yahoo group, and occasional retreats. Harrison shows that sharing humour, insight, difference and conversation became as important for the group members as their common endeavour (doctoral study).

Badenhorst et al. (2013) propose that the non-competitive environment of some groups fosters productivity and collaboration among writers. Participants in her multi-disciplinary, university-based writing group in Newfoundland, Canada, found that membership in a group helped them navigate teaching and administrative duties which typically compete with, or push aside, research and writing. Writers attest that the group is a good way of developing confidence and momentum in writing, without the imposition of external sanctions and surveillance. In this particular group writers have individual writing projects as well as joint ones.

A different perspective is advanced by Lee and Boud (2003) who hold that writing development should be conceptualised as a 'local practice' because 'academic identities, including identities as researchers, are forged, rehearsed and remade in local sites of practice' (2003, 188). Thus writing groups may work particularly well in discipline-specific groups, or in academic departments and research units. Developing writing capacity can foster collegiality, mutuality and sense of community in departments, especially where relationships are weak or fragmented (Aitchison and Lee 2006). One example of how these benefits can be achieved resides in the School of Therapeutic Sciences of our university. The Head of School effectively reduced competing demands on academics (for example teaching and administrative duties) so that one full morning a week could be dedicated to research writing. Not only has this arrangement increased the publication output of individuals and the department, it has had a beneficial impact on collegial relations. Respect, trust and conviviality are increased when writing achievements are celebrated publicly (and with cake) (personal communication with a member of staff, 13 September 2013).

The benefits of functional, ongoing writing groups in terms of building community and collegiality are evident in the examples given above. In the School of Therapeutic Sciences, information about intellectual property, writing style, referencing and publishing was exchanged, and guidance provided by more experienced staff on career planning and strategizing. Writing groups also help to address many of the emotional dimensions of writing which Murray and Moore (2006), cited above, identified as posing barriers to productive writing. At the very least, as Silvia (2007) points out, writing groups can sustain individuals' accountability and help writers meet deadlines.

Observers might point out that while writing groups require fewer resources than courses 
and workshops, they are less visible in the institution than other forms of intervention which may legitimately claim space and time for writing development. Thomson and Kamler (2013, 154) point out some additional difficulties associated with writing groups: they can take a long time to develop and mature, and when they do, they may be difficult for newcomers to enter. Some writers are reluctant or anxious to share their 'untidy' thoughts in writing-in-progress. Some people don't pull their weight, or fail to contribute to meetings. Some do not meet deadlines. In addition, it is difficult to measure (in number of words or quantity and quality of publications) the productivity of individuals and the contributions made to it by the group. Nevertheless, writing groups provide a remedy for many of the emotional, social and cultural issues which prevent academics from writing (Murray and Moore 2006).

\section{Writing mentoring and coaching}

Mentoring and coaching can be used in both academic development and research development to develop 'rich peer relationships' and common projects among colleagues (Lee and Boud 2003). Both mentoring and coaching employ strategies to develop an individual's planning, reflection, motivation and goals, and therefore also relate well to practices associated with building a culture of research writing in local contexts, for example within a department or school, or in a research group. Successful mentoring and coaching relationships are characterised by trust, respect and mutually shared and understood goals. These relationships are usually entered into voluntarily rather than being imposed (Garvey, Stokes and Megginson 2009).

Mentoring is often associated with 'expert' knowledge sharing and advice (Garvey et al. 2009). In an academic context, a mentor could be a senior colleague who draws on his/ her own experience to give advice and make expert recommendations to the mentee. In this case, mentoring is a form of partnership in which the pair respect and like each other, often resulting in longer-term relationship and friendship. Cox, Bachkirova and Clutterbuck (2010) suggest that mentoring is associated with the mentee's desire to progress and achieve. Mentees are often in the process of transition, or facing a challenge, for example, starting a $\mathrm{PhD}$ or beginning to write for publication. Mentoring has learning and development as its core purpose, so it is not surprising that it is recognised as a facilitative model or process for postgraduate supervision (Lee 2007, 686).

Both mentors and coaches can help a writer to identify problems and blockages which inhibit writing, and plan a way forward which will lead to success in writing. There are, however, some distinctions between mentoring and coaching (Wadee, Keane, Dietz and Hay 
2010). Unlike a mentor, a coach is rarely a senior colleague in the same department or institution. A coach is more likely to be a peer or an outsider, trained as a coach, who uses activities, tasks and reflection to help the coachee progress and stay accountable to the goals s/he sets. A coach need not be a researcher or writer herself. When working with a coachee, a coach might probe the coachee's sense of becoming a writer, or work with the coachee to identify the values and characteristics of writing which the coachee wants to emulate or develop. The coach may help the coachee to set goals with respect to writing projects, locate and interact with writing resources and events, and plan activities. Baldwin and Chandler (2002, 12) found that using a writing coach over an extended period of time was a means of providing emotional, informational and instrumental support which resulted in increased levels of empowerment and publication among academic staff. The role of the coach in this case was to offer help, encouragement and support with writing to any staff member who sought the coach's assistance at any stage of their writing.

Mentors and coaches for academic writers and postgraduate students can be highly effective on a number of levels, and may increase the effectiveness of writing courses and workshops, as Kapp et al. (2011) attest. However, professional services can be costly and time consuming, while matching mentors and coaches with writers may also present difficulties (Clutterbuck 2004; Garvey et al. 2009). Mentors who are effective in other roles, for example as researchers, may find that becoming a writing mentor presents different challenges (Murray and Moore 2006; Thomson and Kamler 2013, 158-160). Issues of cost, accountability and selection may mean that hiring a writing coach or consultant is a luxury for a selected few.

\section{PhD bootcamps}

Between 2007 and 2010, $\mathrm{PhD}$ acceleration programmes, known as 'PhD bootcamps' were introduced in several professional schools in our institution, including Health Sciences, Law, and Education, to support early to mid-career academics to complete a $\mathrm{PhD}$ and establish a publication record in peer-reviewed, accredited publications. Over a ten month period, participants completed six courses, including 'Research Writing' 'Time and Stress Management' and 'Speed Reading' presented by the institution's academic staff development centre. Participants also received twelve 60-minute sessions of personal coaching provided by professionally trained academic staff of the university employed in a different school or faculty from the coachee. Most academics indicated in written evaluations and interviews conducted after the programme that the bootcamps increased their productivity, commitment, motivation 
and accountability (Geber 2009; Geber and Bentley 2012). The coaching component helped with exploring ambitions, building confidence, developing life skills and directing energies towards research and writing, reducing the hardships experienced by many staff trying to complete a PhD while working under stressful conditions. In a study of the programme conducted in the Faculty of Health Sciences, Geber and Bentley (2012) concluded that in addition to the benefits described above, there was also an excellent return on (financial) investment for the university from this low cost academic staff development programme.

\section{Writing retreats}

Many academics have difficulty in finding and protecting time for research and writing, especially if teaching and supervision are their main focus of activity. They may also lack the confidence, experience and expertise needed for writing for publication (McGrail et al. 2006). Writing retreats provide dedicated time and space for writing, allowing participants to remove themselves from or 'contain' the practical and emotional demands of daily life (McLeod et al. 2012). Retreats can also develop participants’ repertoire of skills and practices, while increasing motivation to write (Moore et al. 2010). They can increase written academic output and provide support for career development, but the main reason for coming to a writing retreat is to write (Moore et al. 2010).

In the remainder of this section we describe two types of retreat which operate in different parts of our institution.

The Centre for Learning, Teaching and Development (CLTD) retreat is an off-campus, residential retreat held several times a year for 8-10 writers who have completed a Research Writing course conducted by Badenhorst or staff of the Centre (see Castle and Keane 2012). Participants apply by submitting a short motivation of what they intend to accomplish during the retreat. They commit to participating for the full five days. The retreat provides a pleasant time and space for writing where participants work on a project of their choice, typically a conference paper, journal article, research proposal, or thesis chapter. Participants are more often women than men, and may be experienced or novice researchers and writers. They are academics of different ages, length of service and rank, drawn from different disciplines and fields. The retreat is held in a guesthouse with spacious bedrooms for private writing, a large boardroom for communal writing, and a courtyard with many nooks for writing and consultations.

The writing day starts with warm-up activities designed by the facilitators, such as free writing, drawing, or mind mapping, done by hand, using coloured pens and paper, in 
community with others. After 45-60 minutes of this, writers are free to write on their own. The balance of the morning and most of the afternoon are spent writing communally or in solitude, occasionally in consultation with a facilitator or another writer. In the late afternoon writers meet to read aloud excerpts from their work, to solicit and give feedback on their writing. The feedback session often fuels a burst of revision before or after dinner for many writers. In written evaluations of the retreat, writers indicated that they valued the retreats because they provided space to regenerate; time to think, read and write; discursive space; and collegiality. Most writers achieved a 'substantive' completion of writing goals and left the retreat with a framework or plan in place to complete their projects.

The writing retreats held in the School of Economic and Business Sciences (SEBS) originated from a perceived need to increase research and publication in a school which has a high percentage of early career academics and insufficiently research-active senior staff. The main problems identified within the school were lack of 'good time' for writing and research, as well as lack of experience and 'know-how' among junior staff. Two staff members had previously attended a 'Writing for Publication' workshop offered by Kapp et al. (2011) and used the knowledge gained there to design a writing retreat that provided input and support for less experienced writers as well as time and space to write. The retreats are held off campus at a small hotel where writers are offered either a full residential retreat or daily attendance that begins with a shared breakfast. Participants are expected to withdraw from normal work commitments for all five days of the retreat, whether they are in residence or not.

All academics in the school are invited to apply for the retreat and on average, 16-18 participants attend each retreat. Participants are asked to set goals for the retreat and these are posted in the main venue. Participants are free to revise their goals over the course of the retreat, and goals are revisited at the end. Stated goals have included writing parts of a conference paper or journal article such as a literature review, or writing the first draft of a dissertation chapter. In many cases participants' goals are related to gaining knowledge, experience or input from the facilitators on writing techniques. Time is allocated in the mornings to address technical and disciplinary aspects of research writing.

Time is also set aside each day for sharing writing in small groups. Participants are encouraged to take turns to read aloud selections of their writing for other writers to comment on. Although some writers read their work aloud and invite feedback from others, for many writers it takes time to develop trust in others. Younger academics are often on the receiving end of 'supervisor-type' input from senior academics, even seeming to solicit this. A degree of discomfort around the focus on writing is evident, particularly among first-time participants. 
Conversations quickly shift to the more familiar topics of research and research methods. Reorganizing groups to include writers from different disciplines and levels of experience helps to change group dynamics. Yet senior academics seem reluctant to share their own work and tend to give harsh feedback to juniors. Over the week most participants settle into a comfortable routine of writing. Longer, more creative and more readily shared writing emerges. By the end of the five days, most participants feel that they have enjoyed the retreat and achieved progress towards their goals. The main criticism of the retreats come from those wanting more time to write and those not wanting to participate in the feedback sessions.

Both the CLTD and the SEBS retreats aim to foster research writing for staff completing higher degrees and for increased publication for journals, and both retreats are held in pleasant environments removed from the immediate demands of the university. Facilitators of both retreats act as repositories of writing techniques and practices, negotiate ground rules and ways forward, plan and/or negotiate a daily programme, and help participants set and meet meaningful goals. The CLTD retreat groups are smaller than the SEBS groups, and this may positively affect the degree of warmth and collegiality achieved in the CLTD retreat. The School focus of the SEBS retreat has the advantage that synergies can be developed among staff in the same discipline and continued after the event. On the other hand, in the SEBS retreat, true confidentiality and relaxation, retreating from the everyday world of work, including School power relations, is not possible. Participants risk exposure as unproductive writers or inadequate researchers in the presence of senior academics and managers. In the SEBS retreat, facilitators have additional responsibilities for introducing novice writers to writing techniques and practices, while also inducting participants into retreat culture. The writing day is therefore more structured and more didactic than the process-driven CLTD retreat (Benvenuti, Castle and Keane 2013).

Off campus, residential writing retreats are not a quick fix. Nor are they inexpensive. However, as Singh (2012) points out, the expense of a writing retreat can be offset by the income and prestige which arise from increased research output (publications and graduations). As with the other writing strategies reviewed above, support and funding for writing retreats is often contingent on evidence of increased rates of publication by individuals and departments. But for participants, the appeal of retreats may be less tangible, less measurable. The growing sense of being a writer, the emergence of communities of academic writers, shared growth, confidence and ability, are qualities less likely to draw funding for retreats, although they contribute greatly to participants' motivation and enjoyment in writing, and thus to their personal and professional development. 


\section{SUMMARY TABLE}

In Table 1 we distil the main benefits and drawbacks of the five writing strategies we reviewed above into two broad categories - benefits which accrue from assisting writers to tackle the physical and technical challenges of writing, and benefits which accrue when the emotional and social aspects of writing are addressed. A third category shows possible drawbacks or difficulties with positioning the writing strategies in institutions.

Table1: Writing development strategies: benefits and drawbacks

\begin{tabular}{|c|c|c|c|}
\hline Strategy & $\begin{array}{l}\text { BENEFITS: Aspects } \\
\text { which enable writers } \\
\text { to tackle physical and } \\
\text { technical aspects of } \\
\text { writing }\end{array}$ & $\begin{array}{l}\text { BENEFITS: Aspects which } \\
\text { address emotional and } \\
\text { social issues which affect } \\
\text { writers and writing }\end{array}$ & $\begin{array}{l}\text { DRAWBACKS: Constraints } \\
\text { associated with the strategy }\end{array}$ \\
\hline $\begin{array}{l}\text { Writing courses } \\
\text { and workshops }\end{array}$ & $\begin{array}{l}\text { Provide institutionally } \\
\text { sanctioned time and } \\
\text { space for research } \\
\text { writing, especially } \\
\text { writing for publication. } \\
\text { Emphasis placed on } \\
\text { structured activities, } \\
\text { tasks, technical } \\
\text { knowledge and skill in } \\
\text { scholarly writing. }\end{array}$ & $\begin{array}{l}\text { Provide opportunities to build } \\
\text { confidence, collegiality, sense } \\
\text { of achievement and approval. } \\
\text { Overcome feelings of isolation } \\
\text { and being stuck. } \\
\text { Emphasis on interactivity and } \\
\text { dialogue, conceptualizing, } \\
\text { thinking creatively, (self) } \\
\text { reflection. }\end{array}$ & $\begin{array}{l}\text { Sustaining momentum, } \\
\text { productivity, and flow after the } \\
\text { course. } \\
\text { May appear remedial or redundant. } \\
\text { May enhance a sense of scrutiny, } \\
\text { performativity, and } \\
\text { competitiveness, depending on the } \\
\text { nature and design of the course. }\end{array}$ \\
\hline Writing groups & $\begin{array}{l}\text { Establish a collaborative } \\
\text { community of writers, } \\
\text { e.g. in a department, to } \\
\text { improve the quality of } \\
\text { writing through } \\
\text { discussion, and giving } \\
\text { and receiving feedback. } \\
\text { Increase accountability } \\
\text { and completion/ } \\
\text { submission rates. }\end{array}$ & $\begin{array}{l}\text { Support members' motivation } \\
\text { to write, sustain writing over } \\
\text { time to finish a piece of writing. } \\
\text { Provide encouragement; boost } \\
\text { a sense of responsibility, } \\
\text { control and competency. }\end{array}$ & $\begin{array}{l}\text { Groups take a long time to gel, and } \\
\text { may become exclusive or cliquish } \\
\text { over time. } \\
\text { Group members may simply } \\
\text { circulate existing ideas and } \\
\text { practices within the group. Critical } \\
\text { and creative writing may not be } \\
\text { fostered. } \\
\text { Invisible in the institution. }\end{array}$ \\
\hline $\begin{array}{l}\text { Writing } \\
\text { mentoring and } \\
\text { coaching }\end{array}$ & $\begin{array}{l}\text { Develop individuals' } \\
\text { goal setting, planning, } \\
\text { progress towards goals, } \\
\text { as well as accountability } \\
\text { to others. } \\
\text { Stimulate, guide and } \\
\text { support novice writers. }\end{array}$ & $\begin{array}{l}\text { Foster rich, rewarding peer } \\
\text { relationships and joint projects. } \\
\text { Enhance motivation to write. } \\
\text { Provide emotional support. } \\
\text { Increase motivation and self- } \\
\text { efficacy. } \\
\text { Help writers identify ambitions } \\
\text { and direct energies. }\end{array}$ & $\begin{array}{l}\text { Cost of professional services. } \\
\text { Matching mentors with mentees } \\
\text { and coaches with coachees. } \\
\text { Uneven power relations in } \\
\text { mentoring relationships. } \\
\text { Disputes about where responsibility } \\
\text { and accountability lie. }\end{array}$ \\
\hline PhD bootcamps & $\begin{array}{l}\text { Develop a cohort of } \\
\text { writers with the capacity } \\
\text { to complete their own } \\
\text { writing projects and help } \\
\text { others do the same. } \\
\text { Institutionally } \\
\text { sanctioned. Makes good } \\
\text { use of limited or } \\
\text { available resources. }\end{array}$ & $\begin{array}{l}\text { Encourage communication, } \\
\text { discussion, sharing of ideas, } \\
\text { and sharing of experiences } \\
\text { among colleagues. } \\
\text { Participants may gain social } \\
\text { support and social capital from } \\
\text { others in the camp. }\end{array}$ & $\begin{array}{l}\text { May be too harsh, technical- } \\
\text { rational or formulaic to address } \\
\text { individuals' needs for recognition, } \\
\text { emotional support. }\end{array}$ \\
\hline
\end{tabular}




\begin{tabular}{|l|l|l|l|}
\hline Strategy & $\begin{array}{l}\text { BENEFITS: Aspects } \\
\text { which enable writers } \\
\text { to tackle physical and } \\
\text { technical aspects of } \\
\text { writing }\end{array}$ & $\begin{array}{l}\text { BENEFITS: Aspects which } \\
\text { address emotional and } \\
\text { social issues which affect } \\
\text { writers and writing }\end{array}$ & $\begin{array}{l}\text { DRAWBACKS: Constraints } \\
\text { associated with the strategy }\end{array}$ \\
\hline Writing retreats & $\begin{array}{l}\text { Provide dedicated time } \\
\text { and space to write on or } \\
\text { off campus. } \\
\text { Foster productive } \\
\text { writing. } \\
\text { Develop synergies } \\
\text { within a department or } \\
\text { group. } \\
\text { Develop writing 'know } \\
\text { how' in a group. }\end{array}$ & $\begin{array}{l}\text { A pleasant environment makes } \\
\text { participants feel valued. } \\
\text { Build motivation and } \\
\text { confidence. } \\
\text { Increase sense of achievement } \\
\text { and competence. } \\
\text { Develop communities of writers } \\
\text { from those who participate } \\
\text { more than once. }\end{array}$ & $\begin{array}{l}\text { Off-campus retreats may be costly. } \\
\text { Group and power dynamics need } \\
\text { careful management. } \\
\text { Participants may be relucting } \\
\text { share writing. }\end{array}$ \\
\hline
\end{tabular}

\section{REFLECTION AND CONCLUSION}

At the beginning of this article we declared that academics needed more than policy mandates to flourish as writers. This statement reflected our assessment of a situation in which declining government subsidy for public universities had pushed institutional leaders to apply pressure on their own staff and students to generate at least some of the lost income. Academic staff in our own research-intensive university (and in many other institutions, as reported in the national and international literature) are routinely urged to increase the quantity and quality of publications they write, to apply for research grants, and to complete higher degrees. All of these activities generate income for the university and also burnish its reputation. These activities also add to the pressures that academics experience as class sizes grow, students issue new needs and demands, professional and administrative responsibilities increase, and resources shrink.

This is a context in which academics are harassed to 'produce', yet there is little practical knowledge circulating about the writing development strategies available to help them flourish. Hence we arrived at our research question: 'How may those entrusted to provide professional writing support for academics help them flourish as writers?' We believe that research managers and academic staff developers have a vested professional interest in engaging creatively and critically with writing development strategies. Drawing on our humanist philosophy and direct personal experience, we suspected that many university research offices and academic staff development centres could focus too easily on writing strategies which aim to increase productivity and pay too little heed to strategies which aim to address the emotional and social dimensions of writing, such as those identified by Murray and Moore (2006). We drew on Murray and Moore (2006), Badenhorst (2007; 2008) and others to underline the importance of addressing emotional and social issues as well as physical and technical aspects 
of writing.

We then provided a critical review of published literature on five writing development strategies. The strategies were: writing courses and workshops; writing groups; writing mentoring and coaching; PhD bootcamps and writing retreats. Where possible, we shaped our review around the characteristics of the context and participants in the writing strategy; the pedagogy employed to develop writing; and evidence to support the claims made for the strategy. We drew up a table which summarised the main claims (benefits and drawbacks).

Broadly speaking, the review of literature and the summary table show that writing groups and process-oriented writing retreats provide more opportunities to cater for the social and emotional dimensions of writing than other strategies do. This includes activities aimed at developing a collaborative community with others or developing synergies with others, through dialogue, engagement, and getting into the flow of writing.

Structured writing courses and workshops, PhD bootcamps, less structured, processoriented workshops and courses, writing groups, and writing retreats highlight the benefits of experiential and social learning for academics, and often provide the emotional and social support needed for some academics to undertake and complete a substantial writing project. Research managers and academic staff developers can help academics to flourish as writers by considering the benefits and drawbacks of the strategies and purposefully designing and sequencing activities to achieve their desired goals.

\section{ACKNOWLEDGMENTS}

The authors acknowledge and thank our colleague Susan Benvenuti for her contributions to this article.

\section{REFERENCES}

Aitchison, C. and A. Lee. 2006. Research writing: Problems and pedagogies. Teaching in Higher Education 11(3): 265-278.

Badenhorst, C. 2007. Research writing: Breaking the barriers. Pretoria: Van Schaik.

Badenhorst, C. 2008. Dissertation writing: A research journey. Pretoria: Van Schaik.

Badenhorst, C. 2010. Productive writing: Becoming a prolific academic writer. Pretoria: Van Schaik.

Badenhorst, C. M., S. Penny, S. Pickett, R. Joy, J. Hesson, G. Young, H. McLeod, D. Vaandering and X. Li. 2013. Writing relationships: Collaboration in a faculty writing group. All Ireland Society for Higher Education - Journal 5(1): 1001-1026.

Baldwin, C. and G. E. Chandler. 2002. Improving faculty production output: The role of a writing coach. Journal of Professional Nursing 18(1): 8-15.

Benvenuti, S., J. Castle and M. Keane. 2013 'Writing retreats in response to the "incessant demands” of 
the university.' 4th World Conference on Learning, Teaching and Educational Leadership. October 27-29, 2013. Barcelona, Spain. www.sciencedirect.com

Boice, R. 1990. Professors as writers: A self-help guide to productive writing. Stillwater, OK: New Forums.

Boice, R. and F. Jones. 1984. Why academicians don't write. The Journal of Higher Education 55(5): 567-582.

Castle, J. and M. Keane. 2012. Developing an experiential research writing retreat experientially. South African Journal of Higher Education 26(3): 422-440.

Clutterbuck, D. 2004. Graduate Mentoring. $2^{\text {nd }}$ edition. London: Chartered Institute of Personnel and Development.

Cox, E., T. Bachkirova and D. Clutterbuck. 2010. The complete handbook of coaching. London, Thousand Oaks CA, New Delhi, Singapore: Sage Publications.

Devlin, M. and A. Radloff. 2014. A structured writing programme for staff: Facilitating knowledge, skills, confidence and publishing outcomes. Journal of Further and Higher Education 38(2): 230248.

Dickson-Swift, V., E. L. James, S. Kippen, L. Talbot, G. Verrinder and B. Ward. 2009. A non-residential alternative to off-campus writers' retreats for academics. Journal of Further and Higher Education 33(3): 229-239.

Dwyer, A., B. Lesis, F. McDonald and M. Burns. 2012. It’s always a pleasure: Exploring productivity and pleasure in a writing group for early career academics. Studies in Continuing Education. 34(2): 129-144.

Elbow, P. 1981. Writing with power: Techniques for mastering the writing process. Oxford: Oxford University Press.

Elbow, P. 1973. Writing without teachers. Oxford: Oxford University Press.

Garvey, R., P. Stokes and D. Megginson. 2009. Coaching and mentoring: Theory and practice. Los Angeles, London, New Delhi, Singapore and Washington: Sage Publications.

Geber, H. 2009. Research success and structured support: Developing early-career academics in higher education. South African Journal of Higher Education 23(4): 674-689.

Geber, H. and A. Bentley. 2012. Can low-cost support programmes with coaching accelerate doctoral completion in Health Sciences Faculty academics? Perspectives in Education 30(3): 30-38.

Gee, J. P. 2000. Identity as an analytic lens for research in education. Review of Research in Education 25: 99-125.

Grant, B. 2006. Writing in the company of other women: Exceeding the boundaries. Studies in Higher Education 31(4): 483-495.

Grant, B. and S. Knowles. 2000. Flights of imagination: Academic women (be)coming writers. International Journal for Academic Development 5(1): 6-19.

Harrison, L. 2011. PaperHeaDs: Living doctoral study, developing doctoral identity. Bern: Peter Lang.

Janks, H. 2012. The discipline and craft of academic writing: Building writing capacity in institutions of higher education. Reading \& Writing 3(1): Art. \#25, 9 pages. from http://dx.doi.org/10.4102/ rw.v3i1.25 (accessed 25 June 2013).

Kapp, C. A., R. M. Albertyn and B. L. Frick. 2011. Writing for publication: An intervention to overcome barriers to scholarly writing. South African Journal of Higher Education 25(4): 741-759.

Lave, J. and E. Wenger. 1991. Situated learning: Legitimate peripheral participation. Cambridge: Cambridge University Press.

Lee, A. M. 2007. Developing effective supervisors: Concepts of research supervision. South African Journal of Higher Education 21(4): 680-693.

Lee, A. and D. Boud. 2003. Writing groups, change and academic identity: Research development as local practice. Studies in Higher Education 28(2): 187-200. 
MacLeod, I., L. Steckley and R. Murray. 2012. Time is not enough: Promoting strategic engagement with writing for publication. Studies in Higher Education 37(6): 641-654.

McGrail, M. R., C. M. Rickard and R. Jones. 2006. Publish or perish: A systematic review of interventions to increase academic publication rates. Higher Education Research and Development 25(1): 19-35.

Merriam, S. B. 2009. Qualitative research: A guide to design and implementation. San Francisco: John Wiley and sons.

Moore, S. 2003. Writing retreats for academics: Exploring and increasing the motivation to write. Journal of Further and Higher Education 27(3): 333-342.

Moore, S., M. Murphy and R. Murray. 2010. Increasing academic output and supporting equality of career opportunity in universities: Can writers' retreats play a role? The Journal of Faculty Development 24(3): 21-30.

Murray, R. 2012. 'It's not a hobby': Reconceptualising the place of writing in academic work. Higher Education 66: 79-91.

Murray, R. 2013. Writing for academic journals. $2^{\text {nd }}$ Edition. Maidenhead and New York: Open University Press.

Murray, R. and S. Moore. 2006. The handbook of research writing: A fresh approach. New York: McGraw Hill and Open University Press.

Silvia, P. 2007. How to write a lot. A practical guide to productive academic writing. Washington, DC. American Psychological Association.

Singh, R. J. 2012. Promoting writing for research: The 'writing retreat' model. South African Journal of Higher Education 26(1): 66-76.

Thomson, P. and B. Kamler. 2013. Writing for peer reviewed journals: Strategies for getting published. London and New York: Routledge.

Wadee, A. A., M. Keane, T. Dietz and D. Hay. 2010. Effective PhD supervision mentoring and Coaching. $2^{\text {nd }}$ Edition. South Africa-Netherlands research Programme on Alternatives in Development SANPAD. Amsterdam: Rosenberg Publishers.

Weaver, D., D. Robbi and A. Radloff. 2013. Demystifying the publication process - a structured writing program to facilitate dissemination of teaching and learning scholarship. International Journal for Academic Development. http://dx.doi.org/10.1080/ 1360144X.2013.805692 (accessed 25 June 2013).

Wenger, E. 1998. Communities of practice: Learning, meaning and identity. Cambridge: Cambridge University Press. 